COLON CANCER

\title{
Duodenal adenomatosis in familial adenomatous polyposis
}

\author{
S Bülow, J Björk, I J Christensen, O Fausa, H Järvinen, F Moesgaard, H F A Vasen, the DAF Study \\ Group
}

Background: The prevalence of duodenal carcinoma is much higher in familial adenomatous polyposis (FAP) than in the background population, and duodenal adenomatosis is found in most polyposis patients. Aims: To describe the long term natural history of duodenal adenomatosis in FAP and evaluate if cancer prophylactic surveillance of the duodenum is indicated.

Methods: A prospective five nation study was carried out in the Nordic countries and the Netherlands. Patients: A total of 368 patients were examined by gastroduodenoscopy at two year intervals during the period 1990-2001.

See end of article for Results: At the first endoscopy, $238(65 \%)$ patients had duodenal adenomas at a median age of 38 years. authors' affiliations Median follow up was 7.6 years. The cumulative incidence of adenomatosis at age 70 years was $90 \%$ (95\% confidence interval (Cl) $79-100 \%$ ), and of Spigelman stage IV $52 \%(95 \% \mathrm{Cl} 28-76 \%)$. The probability of an advanced Spigelman score increased during the study period $(p<0.0001)$ due to an increasing number and size of adenomas. Two patients had asymptomatic duodenal carcinoma at their first endoscopy while four developed carcinoma during the study at a median age of 52 years (range 2658). The cumulative incidence rate of cancer was $4.5 \%$ at age 57 years $(95 \% \mathrm{Cl} 0.1-8.9 \%)$ and the risk was higher in patients with Spigelman stage IV at their first endoscopy than in those with stages 0-III $(\mathrm{p}<0.01)$.

Correspondence to:

Polyposis Register,

Hvidovre University

Hospital, DK 2650

Hvidovre, Denmark;

sbulow@dadlnet.dk

Accepted

30 September 2003

Conclusions: The natural course of duodenal adenomatosis has now been described in detail. The high incidence and increasing severity of duodenal adenomatosis with age justifies prophylactic examination, and a programme is presented for upper gastrointestinal endoscopic surveillance.

$\mathrm{D}$ uodenal polyps in familial adenomatous polyposis (FAP) were first described almost a century ago; 1 duodenal carcinoma was reported in $1935^{2}$ and the first series of upper gastrointestinal endoscopic screening was published in 1977. ${ }^{3}$ The increasing use of prophylactic examination and early colectomy has caused a substantial reduction in the incidence of colorectal cancer which has led to improvement in prognosis. ${ }^{4}$ Over the last decades, the pattern of causes of death has changed, and today duodenal cancer is one of the major causes of death. ${ }^{5}$ Duodenal adenomatosis is found in the majority of polyposis patients and may lead to carcinoma development. In 1989, Spigelman et al published an endoscopic and histological classification system for evaluation of the severity of duodenal adenomatosis, ${ }^{6}$ and the Spigelman classification has become the gold standard in several studies of duodenal adenomatosis. ${ }^{7-17}$ Regular upper gastrointestinal endoscopic surveillance of polyposis patients has been recommended ${ }^{17}$ but detailed knowledge of the course and development of duodenal adenomatosis is a necessary condition to justify such a recommendation.

The aims of the present Nordic-Dutch prospective multicentre study were to describe the long term natural history of duodenal adenomatosis, to evaluate if cancer prophylactic endoscopic surveillance of the duodenum is indicated, and possibly to identify subgroups at high risk of carcinoma development.

\section{PATIENTS AND METHODS}

In 1990, patients with histologically verified FAP, aged 20 years or more, in Denmark, Finland, Norway, Sweden, and the Netherlands were invited to undergo regular upper gastrointestinal endoscopy according to a set protocol. Exclusion criteria were previous duodenal or periampullary carcinoma. The study was coordinated from the five national polyposis registries, and patients were examined as outpatients in regional hospitals at intervals of two years during the study period 1990-2001. Sedation included diazepam or midazolam, and butylscopolamine was added for duodenal examination. A standard forward viewing endoscope was used. Gastric polyps were biopsied and removed with the exception of typical fundic gland polyposis. The size of the duodenal polyps was measured by an open biopsy forceps, and the Spigelman classification ${ }^{6}$ was adopted for evaluation of endoscopic and histological staging. In patients without visible polyps, at least six random biopsies were taken from the mucosal folds of the second and upper third part of the duodenum, including the papilla region. One pathologist from each country evaluated the biopsies.

The study was organised by a project leader, a study group, and regional contact persons in the examining departments (see appendix). The data were entered into a central database in the Danish Polyposis Register, and the five national ethics committees approved the study. ${ }^{10}$

The Kaplan-Meier method was used to calculate cumulative rates of the endpoints of adenomatosis and adenomatosis Spigelman stage IV as a function of time from entry into the study. The Cox proportional hazards model was used to test for associations between the two endpoints and other covariates. Evaluation of the development of duodenal adenomatosis with time was performed using a generalised linear model assuming a multinomial distribution with cumulative logits as the link function and taking repeated measures into account. Estimates were obtained by generalised estimating equations. ${ }^{18}$ For these calculations, endoscopies were classified as entry, 2, 4, 6, or 8 years, allocating each

Abbreviations: FAP, familial adenomatous polyposis; $H R$, hazard ratio 
endoscopy to the nearest time point. Statistical calculations were done using SAS (v 8.2; SAS Institute, Cary, North Carolina, USA). A p value of less than $5 \%$ was considered significant.

\section{RESULTS}

\section{First endoscopy}

A total of 368 patients ( 182 males and 186 females) entered the study in Denmark $(n=108)$, Finland $(n=65)$, Holland $(\mathrm{n}=35)$, Norway $(\mathrm{n}=59)$, and Sweden $(\mathrm{n}=101)$. Median ages at diagnosis of FAP, at colectomy, and at the first upper gastrointestinal endoscopy in the study were 25 years (range 6-67), 26 years (range 9-67), and 37 years (range 20-81), respectively. Seven patients had various types of local excision of duodenal polyps before entering the study. Fundic gland polyps were seen in 198 (54\%), gastric adenomas in $37(10 \%)$, and gastric hyperplastic polyps in nine $(2 \%)$ patients. Duodenal polyps were seen in 228 patients, in whom histological examination showed adenomas in 209 and normal mucosa in 19. Random biopsies showed adenomatous tissue in 28 patients without visible polyps at endoscopy. In total, 238 patients $(65 \%)$ had duodenal adenomas, of whom $12 \%$ were invisible. Median age at diagnosis of duodenal adenomas was 38 years (range 20-81). The Spigelman classification in 366 classifiable patients was stage 0,123 (34\%); stage I, 55 (15\%); stage II, 97 (27\%); stage III, 64 (17\%); and stage IV, 27 (7\%) (fig 1). Two patients $(0.5 \%)$ had a duodenal carcinoma.

\section{Development of adenomatosis}

The median number of endoscopies was 4 (range 1-5; 131 with five endoscopies, 57 with four, 52 with three, 45 with two, and 83 with one), and the median follow up period was 7.6 years (range $0.5-10.4$ ). The distribution according to Spigelman stage at the follow up endoscopies is shown in fig 1. During the observation period, 12 patients had open duodenotomy with polyp excision. The incidence of adenomas at entry was 65\% (238 patients) and among the remaining 90 patients with follow up, 65\% (95\% confidence interval (CI) 53-77\%) had demonstrated adenoma development within eight years from entry. Median age of patients entering the study with adenomas was 38 years (range 18-

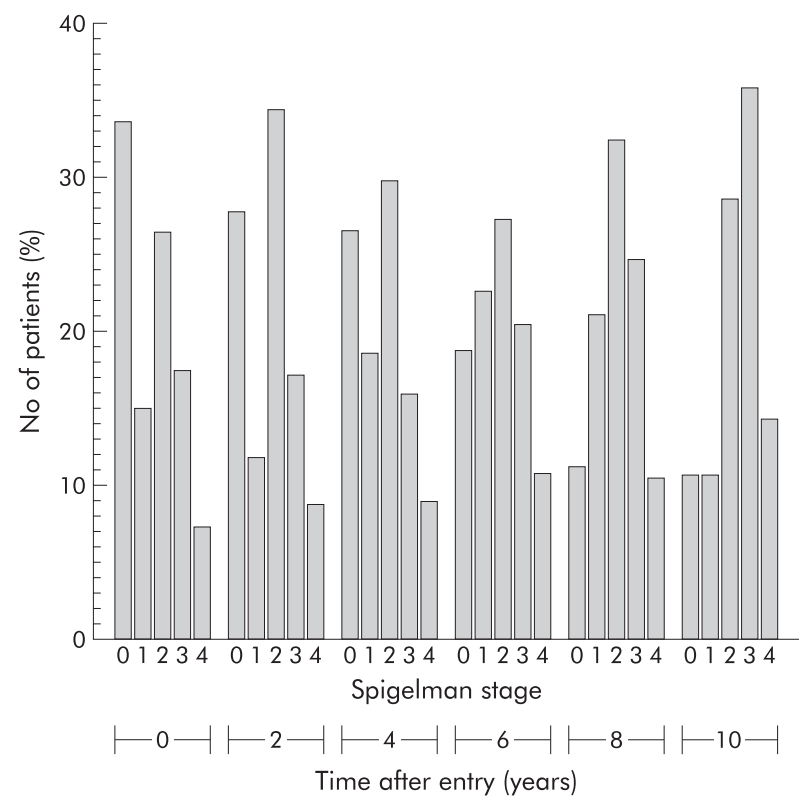

Figure 1 Spigelman classification in classifiable patients in relation to time after entry into the study.
80) whereas median age was 35 years (range 20-75) for those without adenomas and with follow up. The cumulative incidence of adenomatosis development in 128 patients without adenomas at study entry was $50 \%$ after six years (95\% confidence interval (CI) 5-8) and 68\% after eight years (95\% CI 56-80\%) (fig 2). Including age, sex, and time from diagnosis to entry (dichotomised at 15 years) in a Cox proportional hazards model, no significant effect of the covariates was demonstrated $(p=0.51, p=0.98$, and $\mathrm{p}=0.53$, respectively). The cumulative incidence by age in this group was $73 \%$ at age 70 years (95\% CI $57-89$ ). Combining the latter with the age distribution in 238 patients with adenomas at entry, resulted in a $90 \%$ incidence of adenomatosis (95\% CI $74-100 \%$ ) at age 70 years. The incidence of Spigelman stage IV adenomatosis at entry was 7\% (27/366, two missing). Among 339 patients with Spigelman stage $<\mathrm{IV}$ at entry, the cumulative incidence of stage IV was 15\% (95\% CI 10-20\%) (fig 3) at eight years after entry. Including sex, age, time from diagnosis to entry, and Spigelman stage at entry (scored by its value: $0,1,2,3$ ) in a Cox proportional hazards model, age $(\mathrm{p}=0.01$; hazard ratio $(H R)=1.04 ; 95 \%$ CI 1.01-1.07), time from diagnosis to entry $(\mathrm{p}=0.04 ; \mathrm{HR}=2.1 ; 95 \% \mathrm{CI} 1.0-4.3)$, and Spigelman stage $(\mathrm{p}=0.0002 ; \mathrm{HR}=2.0 ; 95 \%$ CI 1.4-2.9) were significant. The cumulative incidence of stage IV among 257 patients with Spigelman stage $<$ IV at entry and with follow up was $52 \%$ at age 70 years ( $95 \%$ CI $28-76 \%$ ).

Evaluation of changes in the components of the Spigelman classification was based on 283/285 patients with at least two endoscopies; two patients without adenomas at the first endoscopy were excluded. The repeated measures model included endoscopy number, adenoma at entry, time from diagnosis to entry, age, and sex, and demonstrated a significant increase in Spigelman stage over time $(p<0.0001)$. Significant covariates were adenoma at entry $(\mathrm{p}<0.0001)$ and time from diagnosis $(\mathrm{p}<0.0001)$ but not age $(p=0.60)$ or sex $(p=0.29)$. The estimated cumulative probabilities are shown in table 1. A similar analysis of histological type suggested no significant changes over time $(p=0.7)$. Dysplasia was also not significant $(p=0.07)$. Size showed a significant increase over time $(p<0.0001)$ adjusted for time from diagnosis $(p=0.001)$ and adenoma at entry $(p<0.0001)$. Similarly, the number of polyps indicated a significant increase $(\mathrm{p}<0.0001)$, with both time from diagnosis as well as adenoma at entry being significant $(\mathrm{p}<0.0001)$.

\section{Duodenal carcinoma}

During the follow up period, four patients (1.1\%) developed a duodenal carcinoma, and the total incidence of carcinoma was $6 / 368$ ( $1.6 \%$; 95\% CI $0.3-2.9 \%)$. Median age at diagnosis

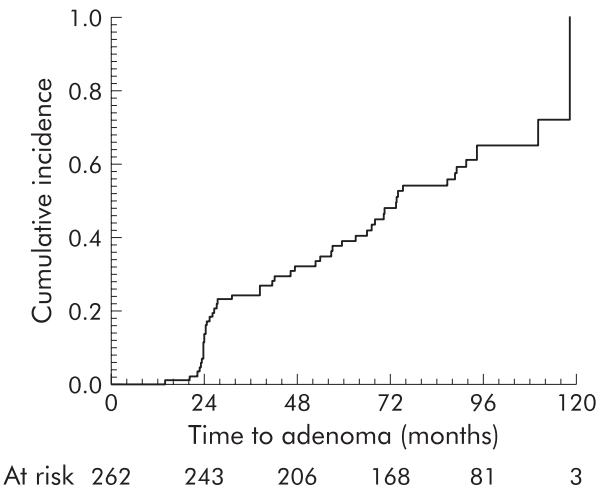

Figure 2 Cumulative incidence of adenomatosis development. 


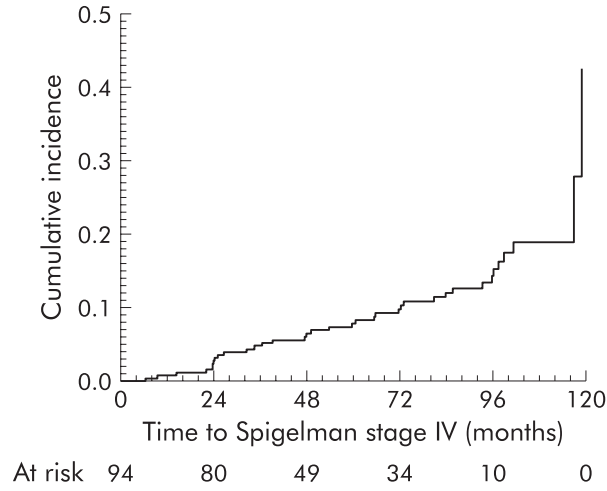

Figure 3 Cumulative incidence of Spigelman stage IV.

of duodenal cancer in the six patients was 52 years (range 26-58) and the cumulative incidence rate was $4.5 \%$ at age 57 years (95\% CI $0.1-8.9 \%)$. Spigelman stages at the previous endoscopies in the four patients who developed duodenal cancer were II-II, IV-III-IV-III, III-III-II-IV, and IV-IV-IVIV, respectively. Among 27 patients with Spigelman stage IV at the first endoscopy, two (7\%) later developed a carcinoma compared with $2 / 339(0.7 \%)$ with Spigelman stages 0-III $(\mathrm{p}<0.01)$. The cumulative crude five year survival after duodenal cancer was 44\% (95\% CL 22-67).

\section{DISCUSSION}

The present study is the largest series of FAP patients followed prospectively with regular upper endoscopy. The advantages of the study were that it was based on five national polyposis registers with a high completeness of registration, it included a 10 year study period, and random biopsies were taken in patients without visible duodenal polyps. The disadvantages were the use of forward viewing endoscopy and decreasing patient compliance throughout the study period. The former may have led to underestimation of the stage of adenomatosis whereas decreasing patient compliance may have had the opposite effect as it cannot be ruled out that more patients with
Table 2 Proposed programme for surveillance and treatment of duodenal adenomatosis

\begin{tabular}{ll}
\hline Spigelman stage 0 & Endoscopy* at intervals of $5 y$ \\
Spigelman stage I & Endoscopyt at intervals of $5 y$ \\
Spigelman stage II & Endoscopyt at intervals of $3 y$ \\
Spigelman stage III & Endoscopyt at intervals of $1-2$ y \\
Spigelman stage IV & $\begin{array}{l}\text { Endoscopic ultrasonography } \\
\text { Consider pancreas sparing or pylorus sparing } \\
\text { duodenectomy }\end{array}$ \\
*Including multiple random biopsies from mucosal folds in patients \\
without visible polyps. \\
tIncluding multiple biopsies from polyps.
\end{tabular}

advanced duodenal adenomatosis continued to participate in the study.

Findings at the first endoscopy demonstrated that the prevalence of duodenal adenomatosis was $65 \%$. This is similar to values of $58-74 \%$ in major series in the literature, which are comparable concerning age at diagnosis of FAP and at the first endoscopy (table 2). It is interesting that $12 \%$ of adenomas were diagnosed only histologically and this underlines the importance of multiple random biopsies in patients without visible polyps. It has been stated that side viewing endoscopy is the ideal procedure for evaluation of duodenal adenomatosis ${ }^{9}$ but as this procedure is only used routinely by endoscopists performing ERCP, we considered the standard use of side viewing endoscopy to be unrealistic in this multicentre study. In our opinion, future studies of the natural course or treatment of duodenal adenomatosis should include a combination of forward and side viewing endoscopy as well as random biopsies. We found the same proportion of adenomatosis Spigelman stage IV as in the Swedish study, ${ }^{14}$ in contrast with the Finnish result of only $2 \% .{ }^{12}$ Median age of patients in the latter study was four years younger, and an updated analysis showed 3.6\% Spigelman stage IV, thus indicating that the difference is probably not real (H Järvinen, personal communication).

The follow up examinations confirmed the results of the Nordic studies and showed that the lifetime risk of duodenal adenomatosis is approaching $100 \% .{ }^{12}{ }^{14}$ We found a lifetime risk of Spigelman stage IV of $52 \%$, with a broad confidence

Table 1 Estimated cumulative probabilities (probability that the stage is less than or equal to $0,1,2$, or 3) for Spigelman stages for patients entering with and without adenomas, and with time from diagnosis to entry dichotomised at 15 years (familial adenomatous polyposis (FAP) time)

\begin{tabular}{llllll}
\hline $\begin{array}{l}\text { No of } \\
\text { endoscopies }\end{array}$ & $\begin{array}{l}\text { Spigelman } \\
\text { stage }\end{array}$ & $\begin{array}{l}\text { +Adenoma FAP } \\
\text { time }<\mathbf{1 5} \mathbf{y}\end{array}$ & $\begin{array}{l}\text { +Adenoma FAP } \\
\text { time }>\mathbf{1 5} \mathbf{y}\end{array}$ & $\begin{array}{l}\text {-Adenoma FAP } \\
\text { time }<\mathbf{1 5} \mathbf{y}\end{array}$ & $\begin{array}{l}\text {-Adenoma FAP } \\
\text { time }>\mathbf{1 5} \mathbf{y}\end{array}$ \\
\hline 1 & 0 & 0.11 & 0.05 & 0.76 & 0.57 \\
1 & 1 & 0.38 & 0.17 & 0.92 & 0.84 \\
1 & 2 & 0.75 & 0.56 & 0.99 & 0.97 \\
1 & 3 & 0.93 & 0.85 & 1.00 & 0.99 \\
2 & 0 & 0.09 & 0.04 & 0.69 & 0.49 \\
2 & 1 & 0.26 & 0.13 & 0.90 & 0.79 \\
2 & 2 & 0.68 & 0.48 & 0.98 & 0.96 \\
2 & 3 & 0.91 & 0.81 & 1.00 & 0.99 \\
3 & 0 & 0.09 & 0.04 & 0.71 & 0.51 \\
3 & 1 & 0.28 & 0.14 & 0.90 & 0.80 \\
3 & 2 & 0.70 & 0.50 & 0.98 & 0.96 \\
3 & 3 & 0.91 & 0.82 & 1.00 & 0.99 \\
4 & 0 & 0.06 & 0.03 & 0.61 & 0.41 \\
4 & 1 & 0.20 & 0.10 & 0.86 & 0.72 \\
4 & 2 & 0.60 & 0.39 & 0.97 & 0.94 \\
4 & 3 & 0.88 & 0.75 & 0.99 & 0.99 \\
5 & 0 & 0.04 & 0.02 & 0.50 & 0.30 \\
5 & 1 & 0.14 & 0.06 & 0.79 & 0.62 \\
5 & 2 & 0.49 & 0.29 & 0.96 & 0.91 \\
5 & 3 & 0.81 & 0.65 & 0.99 & \\
\hline
\end{tabular}




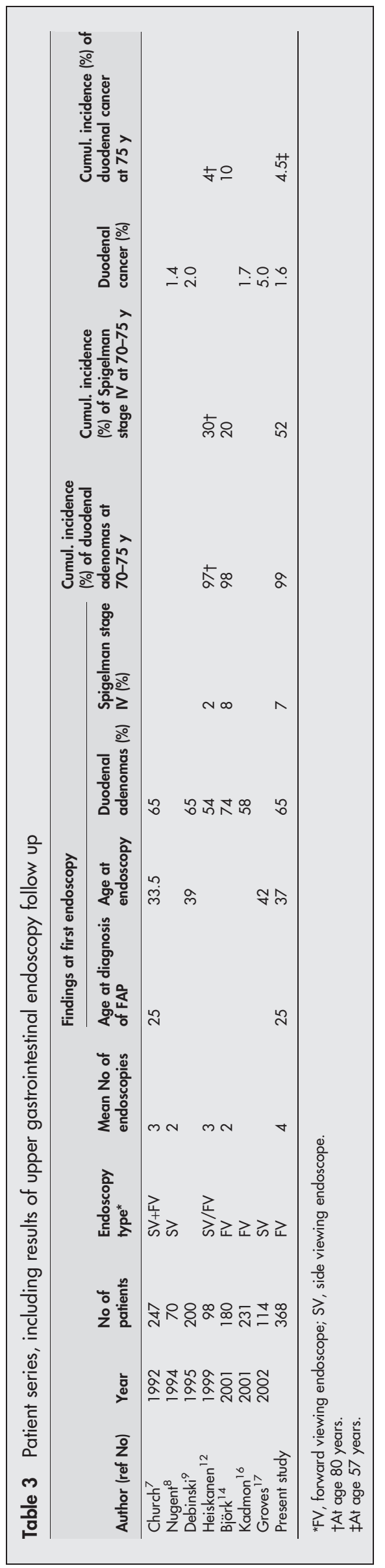

interval, compared with 30\% in the Finnish study ${ }^{12}$ and $20 \%$ in the Swedish study. ${ }^{14}$ The explanation for these discrepancies could be statistical uncertainty (at age 60 years the cumulated incidence was $22 \%$ ), different biopsy policies, and different observation periods. In the Swedish study, only the papilla region was included, and the Spigelman classification was calculated without considering the remaining duodenum. In the Finnish study, the observation period was three years shorter than in our present study.

Detailed analysis of changes in Spigelman classification during the study period demonstrated an increasing number of polyps and size of polyps but no statistically significant change in histological type or degree of dysplasia. This resulted in an overall worsening of the Spigelman score and stage with time. The results in the literature concerning a possible change in Spigelman stage with time are confusing, as some studies report little or no change ${ }^{8{ }^{11}}$ while others have shown $50-75 \%$ progression. ${ }^{12}{ }^{13}$ Our present results are based on a high number of patients followed regularly for 10 years, with an improved statistical method of evaluation. Twelve patients had duodenal polyp excision, and periodic sulindac treatment may have been used in a small number of patients for rectal adenomatosis or desmoid tumours. The influence of this on the development or progression of duodenal adenomatosis is however considered minimal. ${ }^{14}$ Therefore, we believe that our results are valid and indicate that the Spigelman stage will progress with time and patient age, as recently indicated. ${ }^{15}$ The unchanged distribution of histological type with time was expected but the lack of change in degree of dysplasia is surprising and conflicts with the increasing proportion of patients with Spigelman stage IV with time. It is possible that severe degree of dysplasia should add more points to the total Spigelman score and therefore we propose that validation of the Spigelman classification should be undertaken. This could be done in the setting of a multicentre study under the auspices of the Leeds Castle Polyposis Group.

The overall incidence of $1.6 \%$ for duodenal carcinoma in this five nation study is similar to most other series ${ }^{8916}$ but lower than in a recent 10 year follow up study from St Mark's Hospital. ${ }^{17}$ During follow up, carcinoma developed in 2/26 patients with Spigelman stage IV at their first endoscopy compared with 3/11 in the Swedish study ${ }^{14}$ and 4/11 in the St Mark's study. ${ }^{17}$ These values are small and probably not different, thus indicating a higher risk of carcinoma development in patients with Spigelman stage IV than in those with stages $0-$ III. This is another indication of the existence of a duodenal adenoma-carcinoma sequence similar to the well documented sequence in the colon and rectum.

The ideal treatment of duodenal adenomatosis includes complete and lasting destruction of adenomas with a minimum risk of complications and no functional problems. Such a treatment is not yet available but several options have been tried. Endoscopic treatment with Nd-YAG laser or electrocautery implies a risk of perforation and pancreatitis, and requires repeated endoscopies. ${ }^{19}$ Photodynamic therapy seems promising but has not yet been validated. ${ }^{20}$ Duodenotomy with polypectomy is feasible but inevitably leads to recurrence. ${ }^{21}$ Radical surgical treatment has included total pancreatico-duodenectomy (Whipple's operation), which is presently used only in patients with carcinomas. A less comprehensive procedure is recommended as a cancer prophylactic operation in patients with severe adenomatosis: pylorus sparing or pancreas sparing duodenectomy result in few complications and good quality of life. ${ }^{22}$ Pharmacological trials have included sulindac, calcium, calciferol, and celecoxib. In small series, sulindac had little ${ }^{23}$ or no effect, ${ }^{24} 25$ and calcium and calciferol had no effect. ${ }^{25}$ A randomised controlled trial showed that celecoxib $800 \mathrm{mg}$ daily resulted 
in a reduction in duodenal adenomatosis ${ }^{26}$ but there are as yet no long term results concerning adenomatosis development or a cancer protective effect.

Several studies have tried to identify a genotype-phenotype relation between specific mutation sites of the APC gene and the severity of duodenal adenomatosis but the results have been inconsistent. Five studies indicated correlations with mutations in codon $157-416,,^{27}$ codon $279-1309,{ }^{28}$ exon $15,{ }^{29}$ after codon $1400,{ }^{30}$ and exon $10-15,{ }^{31}$ respectively, whereas two studies found no correlation between mutation sites and the severity of adenomatosis ${ }^{31}{ }^{32}$ or carcinoma development. ${ }^{17}$

During the last decades, endoscopic surveillance of the duodenum has been recommended. An evaluation of the effect of such a policy showed a lifetime risk of 3-5\% of duodenal cancer, and decision analysis demonstrated that regular surveillance resulted in an increase in life expectancy of seven months. ${ }^{33}$ Endoscopic ultrasonography has been recommended in patients with Spigelman stages III-IV to ensure that invasive growth has not occurred. ${ }^{9}$ A recent study presented a detailed surveillance programme, including endoscopy at intervals of $1-5$ years depending on the Spigelman stage. Patients with stages II and III are considered for chemoprevention and endoscopic treatment, and those with stage IV should be offered a pancreas preserving duodenectomy. ${ }^{17}$

The present results indicate that regular endoscopic surveillance of the duodenum should be offered to all FAP patients, and our proposed surveillance programme is shown in table 3. The first endoscopy should be carried out at the age of 30 years and include multiple random biopsies taken from the duodenal mucosa in patients without visible polyps. We find the present evidence of endoscopic therapy too weak to justify a general recommendation outside specialised centres. Endoscopic ultrasonography is recommended for evaluation of patients with Spigelman stage IV, severe dysplasia, or large adenomas in order to ensure that invasive growth can be ruled out. In order to delay progression to Spigelman stage IV, it seems justified to treat patients with stage III with celecoxib $800 \mathrm{mg}$ daily. Patients with Spigelman stage IV should be informed about cancer prophylactic surgery. Endoscopic surveillance (including endoscopic ultrasonography) and chemoprevention are recommended at intervals of three months in patients who are not suitable or refuse surgery.

In conclusion, the long term natural history of duodenal adenomatosis in FAP is now known in detail and it has been documented that the incidence and severity of adenomatosis increase with age. There is thus convincing evidence to justify recommendation of regular endoscopic surveillance in all FAP patients. Furthermore, a high risk group for carcinoma development (Spigelman stage IV) has been identified. Chemoprevention with celecoxib may prove to delay worsening of duodenal adenomatosis. Patients with Spigelman stage IV should be offered prophylactic surgery, with pancreas preserving or pylorus sparing duodenectomy being the procedures of choice. We propose that the surveillance programme should be evaluated prospectively in an international multicentre study.

\section{ACKNOWLEDGEMENTS}

The study was supported by "Ingeborg Roikjers Fond" and "The Nordic Cooperative Board for Medical Research"

\footnotetext{
Authors' affiliations

S Bülow, F Moesgaard, The Danish Polyposis Register, Hvidovre University Hospital, Copenhagen, Denmark

J Biörk, The Swedish Polyposis Register, Karolinska Sjukhuset, Stockholm, Sweden

I J Christensen, The Finsen Laboratory, Copenhagen, Denmark
}

O Fausa, The Norwegian Polyposis Register, Rikshospitalet, Oslo, Norway

H Järvinen, The Finnish Polyposis Register, Helsinki University Central Hospital, Helsinki, Finland

H F A Vasen, The Dutch Polyposis Register, The Netherlands Foundation for the Detection of Hereditary Tumours, Leiden, the Netherlands

\section{APPENDIX}

The DAF Study Group included: H Järvinen, A Kahri, and J-P Mecklin (Finland); T Alm, J Björk, R Hultcrantz, and C Rubio (Sweden); S Norheim Andersen, A Bakka, and O Fausa (Norway); G Griffioen, F Nagengast, GJA Offerhaus, and H Vasen (the Netherlands); S Bülow, IJ Christensen, H Højen, F Moesgaard, AM Mogensen, and LB Svendsen (Denmark).

The regional contact persons included: OB Andersen, J La Cour Andersen, C Kirk Axelsson, I Balslev, T Bremholm Sørensen, F Burchharth, HE Bøgh, P Crone, A Fischer, HJ Frederiksen, O Hart Hansen, H Harling, KE Juul Jensen, A Skov Jensen, V Jensen, J Jepsen, P Jess, A Kruse, E Larsen, S Laurberg, A Lauridsen, A Marckmann, O Lawaetz, G Madsen, $\mathrm{T}$ Nilsson, V Møller Pedersen, H Raskov, PC Rasmussen, O Roikjær, N Qvist, K Sørensen, T Bonnesen, P Wamberg, C Werner, and M Øster (Denmark); J-P Mecklin, A-L Karvonen, M Pääkkönen, and I Kellokumpu (Finland) EMH Matthus-Vliegen, $\mathrm{P}$ de Ruyter, and B Taal (Holland) and L-K Enander, K Furugård, D-A Hallbäck, and H-O Håkansson (Sweden).

\section{REFERENCES}

1 Funkenstein O. Über Polyposis intestinalis. Z Klin Med Berlin 1904; $55: 236-48$

2 Cabot RC. Case records of the Massachusetts General Hospital. Case 21061. N Engl J Med 1935;212:263-8.

3 Yao T, lida M, Ohsato K, et al. Duodenal lesions in familial polyposis of the colon. Gastroenterology 1977;73:1086-92.

4 Bülow S, Bülow C, Nielsen TF, et al. Centralized registration, prophylactic examination, and treatment results in improved prognosis in familial adenomatous polyposis. Results from the Danish Polyposis Register. Scand J Gastroenterol 1995;30:989-93.

5 Arvanitis ML, Jagelman DG, Fazio VW, et al. Mortality in patients with familial adenomatous polyposis. Dis Colon Rectum 1990;33:639-42.

6 Spigelman AD, Williams CB, Talbot IC, et al. Upper gastrointestinal cancer in patients with familial adenomatous polyposis. Lancet 1989;2:783-5.

7 Church JM, McGannon E, Hull-Boiner S, et al. Gastroduodenal polyps in patients with familial adenomatous polyposis. Dis Colon Rectum 1992;35:1170-3.

8 Nugent KP, Spigelman AD, Williams CB, et al. Surveillance of duodenal polyps in familial adenomatous polyposis: progress report. J R Soc Med 1994;87:704-6.

9 Debinski HS, Spigelman AD, Hatfield A, et al. Upper intestinal surveillance in familial adenomatous polyposis. Eur J Cancer 1995;31A:1149-53.

10 Bülow S, Alm T, Fausa O, et al. Duodenal adenomatosis in familial adenomatous polyposis. DAF Project Group. Int J Colorectal Dis 1995; 10:43-6.

11 Burke CA, Beck GJ, Church JM, et al. The natural history of untreated duodenal and ampullary adenomas in patients with familial adenomatous polyposis followed in an endoscopic surveillance program. Gastrointest Endosc 1999;49:358-64.

12 Heiskanen I, Kellokumpu I, Järvinen H. Management of duodenal adenomas in 98 patients with familial adenomatous polyposis. Endoscopy 1999;31:412-16.

13 Saurin JC, Ligneau B, Lepretre J, et al. Prospective evaluation of duodenal polyposis progression in familial adenomatous polyposis (FAP) patients, and genotype-phenotype correlation. Digestive Disease Week, San Diego, California, USA, 2000: abstract 3603.

14 Björk J, Åkerbrant H, Iselius L, et al. Periampullary adenomas and adenocarcinomas in familial adenomatous polyposis: cumulative risks and APC gene mutations. Gastroenterology 2001;121:1127-35.

15 Mozaar KL, Madlensky L, Berk T, et al. Slow progression of periampullary neoplasia in familial adenomatous polyposis. J Gastrointest Surg 2002;6:831-7

16 Kadmon M, Tandara A, Herfarth C. Duodenal adenomatosis in familial adenomatous polyposis coli. A review of the literature and results from the Heidelberg Polyposis Register. Int J Colorectal Dis 2001;16:63-75.

17 Groves CJ, Saunders BP, Spigelman AD, et al. Duodenal cancer in patients with familial adenomatous polyposis (FAP): results of a 10 year prospective study. Gut 2002;50:636-41

18 Liang K-Y, Zeger SL. Longitudinal data analysis using generalized linear models. Biometrika 1986;73:13-22.

19 Norton ID, Geller A, Petersen BT, et al. Endoscopic surveillance and ablative therapy for periampullary adenomas. Am J Gastroenterol 2001;96:101-6. 
20 Mlkvy P, Messmann H, Debinski H, et al. Photodynamic therapy for polyps in familial adenomatous polyposis - a pilot study. Eur J Cancer 1995;31A:1160-5.

21 Penna C, Phillips RK, Tiret E, et al. Surgical polypectomy of duodenal adenomas in familial adenomatous polyposis: experience of two European centres. Br J Surg 1993;80:1027-9.

22 Sarmiento JM, Thompson GB, Nagorney DM, et al. Pancreas-sparing duodenectomy for duodenal polyposis. Arch Surg 2002;137:557-63.

23 Nugent KP, Farmer KC, Spigelman AD, et al. Randomized controlled trial of the effect of sulindac on duodenal and rectal polyposis and cell proliferation in patients with familial adenomatous polyposis. Br J Surg 1993;80:1618-19.

24 Richard CS, Berk T, Bapat BV, et al. Sulindac for periampullary polyps in FAP patients. Int J Colorectal Dis 1997;12:14-8.

25 Seow-Choen F, Vijayan V, Keng V. Prospective randomized study of sulindac versus calcium and calciferol for upper gastrointestinal polyps in familial adenomatous polyposis. Br J Surg 1996;83:1763-6.

26 Phillips RK, Wallace MH, Lynch PM, et al. A randomised, double blind, placebo controlled study of celecoxib, a selective cyclooxygenase 2 inhibitor, on duodenal polyposis in familial adenomatous polyposis. Gut 2002; $50: 857-60$

27 Enomoto M, Konishi M, Iwama T, et al. The relationship between frequencies of extracolonic manifestations and the position of APC germline mutation in patients with familial adenomatous polyposis. Jpn J Clin Oncol 2000;30:82-8

28 Saurin JC, Ligneau B, Ponchon T, et al. The influence of mutation site and age on the severity of duodenal polyposis in patients with familial adenomatous polyposis Gastrointest Endosc 2002:55:342-7.

29 Norheim Andersen S, Løvig T, Fausa O, et al. Germline and somatic mutations in exon 15 of the APC gene and K-ras mutations in duodenal adenomas in patients with familial adenomatous polyposis. Scand J Gastroenterol 1999:34:611-17.

30 Groves C, Lamlum H, Crabtree $M$, et al. Mutation cluster region, association between germline and somatic mutations and genotype-phenotype correlation in upper gastrointestinal familial adenomatous polypsis. Am J Path 2002;160:2055-61.

31 Matsumoto $T$, lida $M$, Kobori $Y$, et al. Genetic predisposition to clinical manifestations in familial adenomatous polyposis with special reference to duodenal lesions. Am J Gastroenterol 2002;97:180-5.

32 Sanabria JR, Croxford R, Berk TC, et al. Familial segregation in the occurrence and severity of periampullary neoplasms in familial adenomatous polyposis. Am J Surg 1996;171:136-40.

33 Vasen HF, Bülow S, Myrhøj T, et al. Decision analysis in the management of duodenal adenomatosis in familial adenomatous polyposis. Gut 1997:40:716-19.

\section{GI SNAPSHOT}

\section{Large bowel obstruction due to a benign uterine leiomyoma}

\section{Question}

A 44 year old woman was admitted with a two week history of colicky abdominal pain, vomiting, and constipation. Past medical history included Ehlers Danlos syndrome type IV with a history of spontaneous retroperitoneal haemorrhage treated conservatively. She was also known to have large uterine leiomyomas for which she was on hormonal therapy and was awaiting a hysterectomy.

On examination she had abdominal distension with generalised vague tenderness and some suprapubic fullness. Digital rectal examination revealed an empty rectum with a large pelvic mass bimanually palpable anteriorly.

Chest $x$ ray was normal but supine abdominal $x$ ray revealed faeces filled distended loops of large bowel with minimal air in the rectum. Routine blood tests were within normal limits. She was initially treated conservatively with laxatives and enemas which did not improve her symptoms. On the fourth day of admission she developed severe colicky abdominal pain, persistent vomiting, gross abdominal distension, and obstipation.

See page 430 for answer

\section{R P C Chaparala}

A S Fawole

N S Ambrose

Department of Academic Surgical Gastroenterology, St James's University Hospital, , Leeds, UK

A H Chapman

Department of Radiology, St James's University Hospital, Leeds, UK
Correspondence to: Mr A S Fawole Department of Academic Surgical Gastroenterology, St James's University Hospital, Beckett St, Leeds LS9 7TF,

UK; pamshina@aol.com

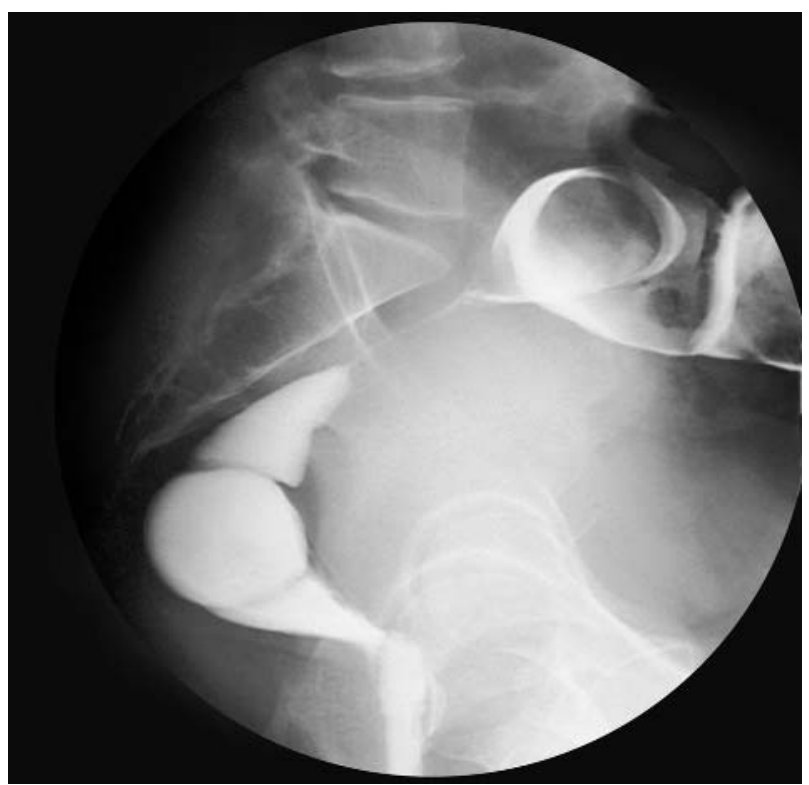

Figure 1 The investigation that was performed is shown. What investigation is demonstrated and what does it show? 